febrile convulsion. In the light of our own and other data ${ }^{7-9}$ it would be surprising if the overall incidence of bacteraemia in children with febrile convulsions is as low as that found by Lewis et al. ${ }^{2}$ We would argue that blood culture should be more frequently done in all young febrile children and not only those who have presented with a seizure. Optimum management of those children found to be bacteraemic must await further study.

Mater Misericordiae Public
Hospitals,
South Brisbane,
Queensland 4101

Department of Child Health,

Alder Hey Children's Hospital, Liverpool L12 2AP

' Winchester TD, Todd JK, Roe MH. Bacteremia in hospitalized children. Am F Dis Child 1977;131 753-8.

2 Lewis MM, Parry JV, Parry RP, et al. Role of viruses

in febrile convulsions. Arch Dis Child 1979;54
869-76.

Bacteremia in febrile children seen in a "walk in" pediatric clinic. $N$ Engl F Med 1973;288:1309-12.

Teele DW, Pelton SI, Grant MJA, et al. Bacteremia in febrile children under 2 years of age/results of cultures of blood of 600 consecutive febrile children seen in a "walk in" clinic. F Pediatr 1975;57:861-7 Bratton L, Teele BW, Klein JO. Outcome of unsuspected pneumococcaemia in children not
initially admitted to hospital. $f$ Pediatr $1977 ; \mathbf{9 0}$ : initially

" Aarimaa T, Peltola H, Ruuskanen O. Pneumococcaemia complicated by meningitis. Arch Dis
Child $1982 ; 57: 392-4$.

Heldrick FJ. Diplococcus pneumoniae bacteremia. Am F Dis Child 1970;119:12-17.

Torphy DE, Roy CG. Occult pneumococcal bacteremia. Am F Dis Child 1970;119:336-8.

Burke JP, Klein JO, Gezon HM, Finland M. Pneumococcal bacteremia. Am $\mathcal{f}$ Dis Child 1971;121:353-9.

\section{Erythrapheresis in polycythaemia}

SIR,-I was interested to read the report of erythrapheresis in patients with polycythaemia secondary to hypoxic lung disease $(12 \mathrm{Feb}-$ ruary, $\mathrm{p}$ 511). I noticed that no mention was actually made of blood volume estimation, which leaves the question of whether the individual patients were suffering from true or relative polycythaemia unanswered. In a sense the distinction may be unimportant since a raised erythrocyte sedimentation rate (or haemoglobin) from whatever cause is associated with an increased morbidity and mortality. ${ }^{1-3}$ The authors compare the merits of their techniques with other methods for reducing red cell mass-for example, by venesection-"which may have fatal consequences" and take a long time to achieve a similar result, ${ }^{4}$ as does continuous oxygen administration. ${ }^{5}$ They kindly quote my original paper on exchange transfusion ${ }^{6}$ but state, "Isovolaemic exchange transfusion with the plasma expander dextran 40 allows more rapid lowering of packed cell volume, but it must be infused over about 12 hours and causes fluid shifts between vascular compartments." In fact no mention was made of having to infuse dextran 40 over about 12 hours. The only reference to time was in an individual case where $2000 \mathrm{ml}$ of blood was replaced safely by a similar volume of dextran 40 within 75 minutes. I think the authors are confusing the details with a paper describing exchange transfusion with dextran 40 in polycythaemia secondary to hypoxic lung disease ${ }^{7}$ (to which no actual reference is made). Here the beneficial results accord remarkably similarly to those found by using erythrapheresis. Although a coauthor in that trial, I have never specified that a dextran infusion needs to be kept running after the procedure unless it is indicated in its own right irrespective of the procedure.

There are, of course, technical problems in venesecting thick sticky blood. Our present practice therefore is to insert a green "medicut" catheter into a radial artery and to lead blood away via a transfusion giving set. ${ }^{8}$ By using the thumbscrew clamp one can precisely regulate the rate at which blood is taken to the rate of infusion. Dr Wedzicha and his colleagues are correct in saying that dextran 40 causes fluid shift. It is hyperoncotic and when transfused rapidly will increase the circulating blood volume by about two "units" for each unit transfused. For this reason we now transfuse the patient with equal quantities of Hartmann's solution and dextran 40 to a volume similar to the blood taken and at the same rate. The infusion is iso-oncotic and abrupt changes in blood volume are avoided. The procedure is simple, safe, fast, cheap, and effective and can be performed anywhere, including in the home, where, for example, a patient with an acute thromboembolic stroke can be treated. Erythrapheresis requires expensive complicated equipment, takes longer, is available in few centres, and cannot be easily transported. It does, however, have the merit that red cells alone are discarded and so as a research tool it can help clarify the issue, "to what can we ascribe the change in the patient's condition following exchange transfusion?" If this "space age leech" does nothing else but draw people's attention to the ill effects of too many red cells ${ }^{2}$ it will justify itself.

Christchurch Hospital,

Christchurch,

Dorset $\mathrm{BH} 23$ JX

${ }^{1}$ Kannel WB, Gordon T, Wolf PA, McNamara P Haemoglobin and the risk of cerebral infarction. The Framingham study. Stroke 1972;3:409-20.

Anonymous. Haemoglobin and the ischaemic foo Lancet 1979 ; i :184-95.

s Burge PS, Johnson WS, Prankerd TAJ. Morbidity and mortality in pseudo polycythaemia. Lancer $1975 ;$; : $1266-9$.

- Constantinidis $\dot{K}$. Venesection fatalities in polycythaemia secondary to lung hypoxia. Practitione $1979 ; 222$ :89-91.

Chamberlain DA, Millard FJC. The treatment of polycythaemia secondary to hypoxic lung disease by continuous $1963 ; 32: 341-50$.

" Gregory RJ. The rapid lowering of haematocrit by exchange transfusion of Rheomacrodex Dextran 40 . exchange transfusion of Rheomacrod
Acta Med Scand 1971;178:551-4.

' Harrison BDW, Gregory RJ, Clark TJH, Scott GW Exchange transfusion with Dextran 40 in polycy thaemia secondary to hypoxic lung disease. $B$ Med F 1971;iv:713-6.

Saumarez RC, Gregory RJ. Exchange transfusion in polycythaemia. Bibliotheca Haemat 1975;41

\section{Personality and socks}

SIR,-I hope that Professor Philip Rhodes's advice on non-verbal communication (26 February, p 706) will linger after his illustrations have faded for life would be drab if every young doctor destined for interview was attired in charcoal or dark grey suit, plain shirt, plain tie, and black shoes. The only discretion allowed seemed to be in the choice of socks, which are not mentioned. This is where personality could show through, subtly indicating an appreciation of those things in life held to be important. Red is likely to be the in colour in industrial towns, while true blue may gain favour in the shires. Socks are generally expected to match, and it would be unwise to hedge bets by wearing one blue and one red. Yellow is becoming fashionable, but, if in doubt, a pattern reflecting the colours of the local football team may be the safer ploy and could put the candidate one up. No special measures are necessary to display the hosiery-indeed, overtightening the braces is contraindicated. Should you be asked to sit behind a table which might obscure the committee's view of the socks bear this with equanimity and rely on the sharp eyes of the assessors to pick up the message (albeit subliminally) as you enter and leave the room.

In seaside resorts absence of socks might go unnoticed during the summer, but holy socks would not be forgiven even in a cathedral city. Unless you can let slip that you own a Rolls silk socks may be the best way of suggesting you are a high flyer. On the other hand (or rather foot), hand knitted socks may appeal to the homely lay member and would be ideal for concealing an electronic device for recording what was promised at interview or, if unsuccessful, what went wrong.

Sheffield S11 9HU

C H SHaw

\section{Computed tomography in the} investigation of dementia

SIR,-Dr J R Bradshaw and others (22 January, $p$ 277) have made an important contribution to the practical approach to the patient with dementia of recent onset by presenting the results of computed tomography of the brain used as part of the diagnostic investigations in 500 consecutive cases. While acknowledging that: "It is clearly impracticable to scan all patients with dementia," the authors identified the presence of headache, focal signs, papilloedema, and speech disorder as helpful diagnostic pointers towards the presence of brain tumours, subdural hematomas, and hydrocephalus-all structural lesions of the brain which are potentially curable and easily recognised on the computed tomogram. I believe, however, that the authors' conclusion is rather timid because their paper contains factual evidence suggesting that a total of 10 clinical features have a positive correlation with the subsequent finding on the computed tomogram of a potentially treatable brain lesion.

The demented patients studied can be divided into two subgroups: 52 individuals with evidence on the computed tomogram of brain tumours, hydrocephalus, or subdural hematomas and 448 individuals without such structural lesions. The 20 clinical features analysed can be construed as testing the presence of the structural lesions mentioned, and their sensitivity and specificity can be calculated by changing the format of the data. For example, focal neurological signs were present in 17 patients with potentially treatable structural lesions and 52 patients without evidence on the computed tomogram of such lesions. The sensitivity of this clinical feature -that is, the proportion of patients correctly identified as having structural lesions-is $44 \%$; its specificity-that is, the proportion of patients without structural lesions who did not have focal neurological signs-is $88 \%$.

After calculating the sensitivity and specificity for each clinical feature one has to determine if these parameters are good enough for the original purpose-that is, the separation, however imperfect, of the two subgroups. This determination is possible by 